\title{
Jean Cocteau, sous la direction de S. Linarès et $\mathrm{S}$. Winter
}

\section{Monia Mezzetti}

\section{Q OpenEdition}

1 Journals

\section{Edizione digitale}

URL: https://journals.openedition.org/studifrancesi/21707

DOI: 10.4000/studifrancesi.21707

ISSN: 2421-5856

\section{Editore}

Rosenberg \& Sellier

\section{Edizione cartacea}

Data di pubblicazione: 1 décembre 2019

Paginazione: 608

ISSN: 0039-2944

\section{Notizia bibliografica digitale}

Monia Mezzetti, «Jean Cocteau, sous la direction de S. Linarès et S. Winter», Studi Francesi [Online], 189 (LXIII | III) | 2019, online dal 01 mars 2020, consultato il 11 novembre 2021. URL: http:// journals.openedition.org/studifrancesi/21707 ; DOI: https://doi.org/10.4000/studifrancesi.21707

Questo documento è stato generato automaticamente il 11 novembre 2021.

\section{(c) (i) (9)}

Studi Francesi è distribuita con Licenza Creative Commons Attribuzione - Non commerciale - Non opere derivate 4.0 Internazionale. 


\title{
Jean Cocteau, sous la direction de S. Linarès et $\mathrm{S}$. Winter
}

\author{
Monia Mezzetti
}

\section{NOTIZIA}

Jean Cocteau, sous la direction de $\mathrm{S}$. Linarès et $\mathrm{S}$. Winter, Paris, Lettres Modernes Minard, 2018, «Création et Intermédialité» 8, 294 pp.

1 Il volume consiste negli Atti del convegno dal titolo Jean Cocteau à la croisée des langages antiques/Jean Cocteau und die Sprachen der Kunst tenutosi a Salisburgo dal 2 al 4 maggio 2013 e organizzato dall'università austriaca in collaborazione con il Centre d'histoire culturelle des sociétés contemporaines dell'Université de Versailles. La varietà dei temi delle comunicazioni riflette la poliedricità di Jean Cocteau, un autore che sarebbe riduttivo definire esclusivamente come poeta o romanziere o saggista o ancora ritrattista, cineasta o coreografo, in ragione proprio dell'ampiezza del suo spettro artistico. Risulta quindi perfettamente funzionale e condivisibile la scelta dei curatori di dare risalto alla bibliografia di Cocteau nelle pagine iniziali del libro (pp. 10-12), dove trovano posto, oltre ai découpages techniques realizzati per il cinema e il balletto, anche $\mathrm{i}$ componimenti poetici, i romanzi, la corrispondenza, i saggi e i disegni (alcuni dei quali riprodotti alle pp. 124-133 e 143-160). L'obiettivo dichiarato dei curatori è quello di scagionare Cocteau dall'accusa di dilettantismo sferrata contro di lui a causa della sua produzione proteiforme e di attirare viceversa l'attenzione sulla motivazione estetica alla base del suo eclettismo. Quest'ultima viene individuata nella «rencontre de la parole avec l'image» (p. 15), ovvero nell'esperienza di attraversamento di diversi ambiti artistici, aventi ciascuno linguaggio e modalità di rappresentazione propri. Nonostante l'insieme dei contributi non sia propriamente suddiviso in sezioni, si possono riconoscere tre nuclei d'interesse: teorico, tematico, tipologico.

2 Al primo di essi afferisce il denso e interessante articolo di S. Winter, co-curatrice del volume, dove si ripercorre la genesi del termine intermedialità, se ne indaga la 
semantica, e ci si interroga sulla legittimità o meno della definizione della poesia di Cocteau come cubista, refutandone la validità a causa della diversità e della specificità dei sistemi semiotici (pp. 33, 35). Altrettanto approfondito e stimolante è il saggio di C. Sauer, dedicato al motivo letterario di ascendenza classica della statua vivente, che Cocteau fa oggetto di rivisitazione nei poèmes en prose (Opéra) e in un film (Sang d'un poète), nel solco di Mérimée (La Vénus d'Ille), del Don Giovanni di Mozart o del Cavaliere di bronzo di Puskin. Danno invece conto delle incursioni dell'autore in campo artistico i saggi centrali: si va così dall'esame dei disegni e dei bozzetti, alle sue riflessioni sulla «perméabilité des frontières des arts» (p. 59), all'uso dell'ipotiposi nei romanzi quale prova dell'effettiva possibilità della commistione tra generi.

Gli ultimi contributi vertono invece su Cocteau cineasta e coreografo di balletti, dove si mette in luce, oltre all'importanza di questo tipo di esperienze nella percezione individuale di sé da parte dell'autore, anche l'itinerario di scoperta del suo interesse e della capacità di contribuirvi con il proprio talento. Ne risulta come il rapporto di Cocteau con la cosiddetta settima arte si sia sviluppato inizialmente sul piano teorico e sulla scia del dibattito sul cinema muto (Le Potomak, Carte blanche), mentre la sua produzione è tale da risultare anti-mimetica (alcuni fotogrammi sono riprodotti alle pp. 188-189). Quanto invece alla sua militanza nel mondo del balletto, emerge come la stesura di livrets de danse sia stata un'attività appagante e per questo non circoscritta nel tempo, bensì ripetuta più volte nell'arco di un trentennio. Come di consueto nella collana in cui è inserito il volume, l'ultimo contributo, a firma di W. Prin-Corti, è indipendente dalla tematica principale e si concentra sui componimenti giovanili di Cocteau. Completano il volume l'Indice dei nomi (pp. 283-288) e i riassunti bilingui (francese e inglese) dei contributi (pp. 289-294). 